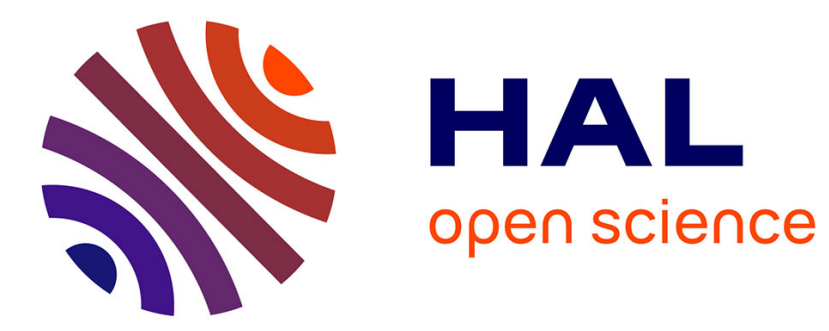

\title{
32-fs Kerr-lens mode-locked Yb:CaGdAlO 4 oscillator optically pumped by a bright fiber laser
}

P Sévillano, Patrick Georges, Frédéric Druon, D Descamps, E Cormier

\section{To cite this version:}

P Sévillano, Patrick Georges, Frédéric Druon, D Descamps, E Cormier. 32-fs Kerr-lens mode-locked Yb:CaGdAlO 4 oscillator optically pumped by a bright fiber laser. Optics Letters, 2014, 39 (20), pp. 6001-6004. 10.1364/OL.39.006001 . hal-01222075

\section{HAL Id: hal-01222075 \\ https://hal.science/hal-01222075}

Submitted on 29 Oct 2015

HAL is a multi-disciplinary open access archive for the deposit and dissemination of scientific research documents, whether they are published or not. The documents may come from teaching and research institutions in France or abroad, or from public or private research centers.
L'archive ouverte pluridisciplinaire HAL, est destinée au dépôt et à la diffusion de documents scientifiques de niveau recherche, publiés ou non, émanant des établissements d'enseignement et de recherche français ou étrangers, des laboratoires publics ou privés. 


\title{
32-fs Kerr-lens mode-locked Yb:CaGdAlO oscillator optically pumped by a bright fiber laser
}

\author{
P. Sévillano ${ }^{1}$, P. Georges ${ }^{2}$, F. Druon ${ }^{2}$, D. Descamps ${ }^{1}$ and E. Cormier ${ }^{1}$ \\ 1. Université Bordeaux-CNRS-CEA-UMR 5107, Centre Lasers Intenses et Applications, 351 Cours de la Libération, F-33405 Talence, France. \\ 2. Laboratoire Charles Fabry, UMR 8501, Institut d'Optique, CNRS, Univ Paris Sud 11, 2 Av. A. Fresnel, 91127 Palaiseau, France \\ *Corresponding author: sevillano@celia.u-bordeauxl.fr \\ Received Month X, XXXX; revised Month X, XXXX; accepted Month X, \\ XXXX; posted Month X, XXXX (Doc. ID XXXXX); published Month X, XXXX
}

\begin{abstract}
In this study, we report on pure Kerr-lens mode-locked $\mathrm{Yb}: \mathrm{CaGdAlO}_{4}$ oscillator optically pumped by a diffraction limited fiber laser. At the repetition rate of $96 \mathrm{MHz}$, several configurations have been studied to achieve either pulse duration of $40 \mathrm{fs}$ with average powers up to the watt level or shorter pulse duration down to $32 \mathrm{fs}$. To the best of our knowledge, this represents the shortest pulse duration ever achieved with an $\mathrm{Yb}$-doped bulk material and the highest average power for sub40 fs Kerr-lens mode-locked Yb-bulk oscillator.

(C) 2014 Optical Society OCIS Codes: 140.4050 Mode-locked lasers, 140.3615 Lasers, ytterbium, 140.7090 Ultrafast lasers
\end{abstract}

During the past decade, Yb-doped crystals have raised a great interest for the generation of high average power ultra-short pulses due to their excellent spectroscopic and thermal properties [1]. Among them, $\mathrm{Yb}: \mathrm{CaGdAlO}_{4}$ (Yb:CALGO) crystal is one of the most promising candidates for sub-50 fs oscillator thanks to its broad and flat emission band [2]. Recent works reported pulse generation as short as $40 \mathrm{fs}$ in this material [3] which is very close to the shortest (35 fs) pulse duration ever obtained from an $\mathrm{Yb}$ doped bulk material based oscillator $[4,5]$. However, these ultra-short pulse oscillators generate average powers never exceeding a few tens of milliwatts. This power limitation results from the unavailability of bright powerful (diffraction limited) pump sources as well as the typical response time of saturable absorbers. The thin-disk technology provides an efficient alternative to significantly increase the average power [6]. Although very impressive powers are demonstrated, the shortest pulse duration reported in Yb:CALGO thin-disk oscillator is limited to $62 \mathrm{fs}$ [7]. Improving the average power while maintaining the pulse duration as short as possible is a challenging goal we aim at achieving making use of pure Kerr-lens mode-locking (KLM) technique combined with high-brightness pumping. By this way, recent works on $\mathrm{Yb}: \mathrm{CaF}_{2}$ reported significant improvements in average power of bulk oscillators with the generation of sub $70 \mathrm{fs}$ with several watts [8]. In this letter, we report on a pure Kerr-lens mode-locked Yb:CALGO oscillator delivering pulse duration of $40 \mathrm{fs}$ at the watt level by means of a powerful single mode, polarized $\mathrm{Yb}$-doped fiber pump emitting around $979.5 \mathrm{~nm}$. After optimization of the output coupler transmission, the oscillator can provide the shortest pulse ever produced in $\mathrm{Yb}$ doped bulk material with pulses as short as $32 \mathrm{fs}$. To the best of our knowledge, it is the first realization of a pure Kerr-lens mode-locking in Yb:CALGO crystal. For this we use a highbrightness optical pumping with a single-mode fiber laser source [9]. After describing the experimental setup, we present the performance of the KLM Yb:CALGO oscillator and discuss the optimization to provide the shortest pulse durations.

The experimental setup of the laser cavity and pumping geometry is sketched in figure 1. We use a 5-mm-long, 2 x $4 \mathrm{~mm}^{2}$ Brewsterangle cut, $\mathrm{Yb}$ :CALGO crystal doped at 5 at. $\%$. It is mounted in a water-cooled copper holder. We have chosen the c-cut orientation to avoid the anisotropy of temperature-dependent refractive index which could appear at high average pump power [10] and to eliminate the polarization state sensitivity in cross-section emission [2]. The Yb:CALGO crystal is positioned between two concave mirrors ( $\mathrm{M}_{1}, \mathrm{M}_{2}, 100$-mm-radius-of-curvature) in a standard X-fold cavity configuration. To compensate astigmatism due to the Brewster-angle incidence, these mirrors are tilted with an angle of $8^{\circ}$. On one side, the cavity ends by a high reflection (HR) mirror and closed on the other side by a 35\% output-coupler (OC). A pair of SF10 prisms separated by a distance of $450 \mathrm{~mm}$ is used for fine intra-cavity dispersion control. The net intracavity group delay dispersion (GDD) is calculated to be close to $-2200 \mathrm{fs}^{2}$ per round trip. All the mirrors used are specified with low group delay dispersion. The cavity is asymmetric with a short arm of $600 \mathrm{~mm}$ and a long one of $900 \mathrm{~mm}$.

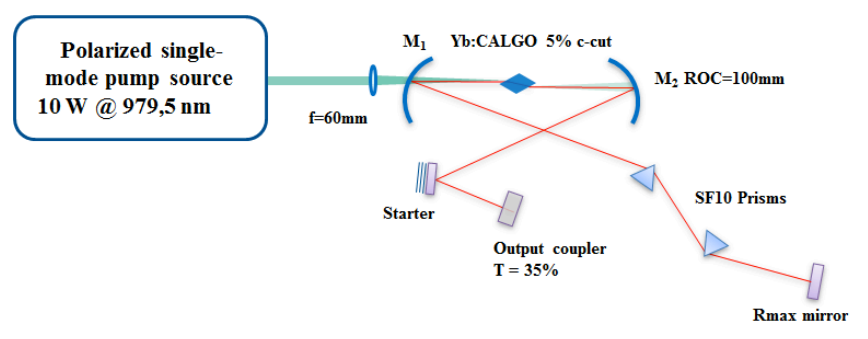

Fig. 1. KLM Yb:CALGO oscillator experimental setup.

The Yb:CALGO crystal is longitudinally pumped by the highbrightness fiber laser through the $\mathrm{M}_{1}$ dichroic mirror (HT for a wavelength below $980 \mathrm{~nm}$ and HR above $1020 \mathrm{~nm}$ ). We use a commercially available diffraction limited polarized pump source $\left(\mathrm{M}^{2}=1.1\right)$ emitting 10 Watts at $979.5 \mathrm{~nm}$ (from Azur Light System). 
The pump radiation is focused into the Yb:CALGO crystal by a $60 \mathrm{~mm}$ focal-length lens. The high spatial quality of the pump beam allows us to obtain a spot radius at the focal plane of $25 \mu \mathrm{m}$ (at $\left.1 / \mathrm{e}^{2}\right)$ leading to a confocal parameter of $3.7 \mathrm{~mm}$ and a maximum pump intensity of $1 \mathrm{MW} / \mathrm{cm}^{2}$. When the pump focus is positioned in the middle of the crystal, absorption saturates leading to an unabsorbed power of $4 \mathrm{~W}$ without laser effect.

First of all, the Yb:CALGO oscillator is characterized in the CW regime. For $10 \mathrm{~W}$ of incident pump power, a maximum output power of $4.5 \mathrm{~W}$ is obtained at the central wavelength of $1044 \mathrm{~nm}$ corresponding to an optical to optical efficiency of $45 \%$. In these conditions, the unabsorbed pump power is $2 \mathrm{~W}$. Since the pump source used in this setup is characterized by a low $\mathrm{M}^{2}$ value, a very good spatial overlap between the laser beam and the gain channel is obtained over the $5 \mathrm{~mm}$ crystal length and leads to a high optical-tooptical efficiency.

In order to discriminate between $\mathrm{CW}$ and ML regimes in the oscillator, the cavity is set at the edge of the stability domain by translating the $\mathrm{M}_{2}$ mirror by $400 \mu \mathrm{m}$ toward the crystal. At this point, the $\mathrm{CW}$ output power drops down to $0.9 \mathrm{~W}$.

(a)

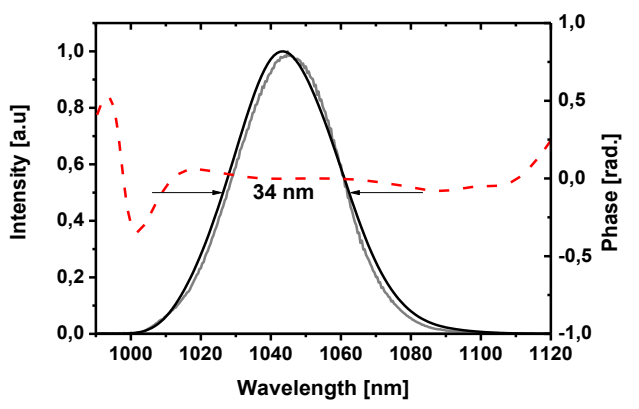

(b)

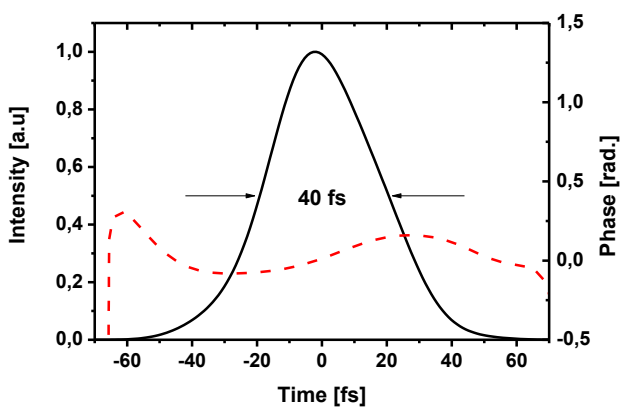

Fig. 2. a) Retrieved SHG-FROG spectrum (black curve) superimposed with the experimental spectrum (grey curve) and spectral phase (dashed red curve). b) Retrieved intensity profile (black curve) and temporal phase (dashed red curve) of the output pulses.

Stable Kerr-lens mode-locking is initiated by vibrating a cavity mirror (starter). When locked, the Yb:CALGO oscillator delivers a pulse train at a repetition rate of $96 \mathrm{MHz}$ with an average power of $1.1 \mathrm{~W}$. Assuming a $\operatorname{sech}^{2}$ pulse shape, an autocorrelation measurement gives a pulse duration of 94 fs (FWHM). The spectrum of the femtosecond pulses is characterized with an optical spectrum analyzer (ANDO AQ6315). It is centered at $1044 \mathrm{~nm}$ with $34 \mathrm{~nm}$ bandwidth (see grey curve in figure 2.a) corresponding to a Fourier-Transform limited duration of $40 \mathrm{fs}$ (FWHM). The slightly chirped output pulses (mainly quadratic phase) are externally compressed with 10 bounces on $-100 \mathrm{fs}^{2}$ chirped mirrors (total transmission of $98 \%$ ) and further characterized with a SHG-FROG device. The retrieved temporal pulse profile (see figure 2.b) indicates the generation of pulse as short as $40 \mathrm{fs}$ (FWHM) at the average power of $1.08 \mathrm{~W}$. The computed autocorrelation width (58 fs) is in very good agreement with the independently measured autocorrelation width of $58 \mathrm{fs}$. At the external compressor output, the time-bandwidth product of the pulses equals 0.373 .

In order to optimize the pulse duration, we investigate the influence of the output coupler transmission. The KLM stability criteria and the soliton formation to provide stable single-pulse regime $[11,12]$ impose a rather constant intracavity peak power irrespective of the OC. We therefore adjust the pump power to fulfill this condition and achieve single-pulse mode-locking. The table 1 summarizes the parameters recorded for various OC transmission values.

Table 1: Spectral and temporal characterization as a function of $\mathrm{OC}$ transmission

\begin{tabular}{lccccc}
\hline $\begin{array}{l}\mathbf{O C} \\
{[\%]}\end{array}$ & $\begin{array}{c}\mathbf{P}_{\text {pump }} \\
{[\mathbf{W}]}\end{array}$ & $\begin{array}{c}\mathbf{P}_{\text {out }} \\
{[\mathbf{m W}]}\end{array}$ & $\begin{array}{c}\boldsymbol{\lambda}_{\mathbf{c}} \\
{[\mathbf{n m}]}\end{array}$ & $\begin{array}{c}\Delta \boldsymbol{\lambda} \\
{[\mathbf{n m}]}\end{array}$ & $\begin{array}{c}\boldsymbol{\Delta} \boldsymbol{\tau} \\
{[\mathbf{f s}]}\end{array}$ \\
\hline 3 & 3,6 & 90 & 1063 & 51 & 32 \\
10 & 4,3 & 280 & 1056 & 46 & 35 \\
20 & 6,3 & 640 & 1052 & 41 & 37 \\
35 & 8,9 & 1100 & 1045 & 34 & 40 \\
\hline
\end{tabular}

Increasing the $\mathrm{OC}$ transmission clearly allows to extract more average power by simply cranking up the pump power accordingly to maintain the intracavity peak power. However, the laser dynamics varies significantly with significant changes on the output pulse spectrum.

Similar to other Yb-doped materials, the gain cross section is a function of both the wavelength and the population inversion in the crystal. In our case, we observe a red shift of the central wavelength for decreasing $\mathrm{OC}$ transmission. This observation is confirmed by our dynamical gain calculations based on absorption and emission cross-sections (from [13]) weighted by the population inversion and where we estimate that the cavity losses are mainly attributed to the OC. We estimated for a $35 \%$ OC transmission an inverted population ratio $(\beta)$ of $10.7 \%$ with a maximum gain cross-section centered at $1045 \mathrm{~nm}$. At contrast, for a $3 \%$ OC transmission, we calculated a $\beta$ of $3.9 \%$ with a gain cross-section maximum at $1063 \mathrm{~nm}$.

Additionally to the spectral shift, we noticed an enhancement of the spectral bandwidth when the OC transmission is reduced. The above gain model also agrees with the latter tendency. However, the increase of the spectral bandwidth cannot be explained solely by the gain cross-section evolution. In fact, it is known that the GDD of dichroic mirror is not well controlled in the spectral range where the coating reflectivity varies significantly. To evaluate this effect on the output spectrum, we replaced $\mathrm{M}_{2}$ (sub-cavity mirror with a flat reflectivity and constant GDD) by the same dichroic concave mirror as $\mathrm{M}_{1}$ thus highlighting the contribution of the net GDD. In figure 3, we compare spectra recorded with one and two dichroic mirrors for a $10 \%$ OC transmission. Also displayed is the net intracavity GDD for each case. It is clearly shown that the femtosecond pulse tends to red shift in order to overlap with a spectral region where GDD is as constant as possible. However, the addition of the second dichroic mirror deteriorates the intracavity GDD flatness and leads to a reduction of the spectral bandwidth from $46 \mathrm{~nm}$ (1 dichroic mirror) to $40 \mathrm{~nm}$ (2 dichroic mirrors). Moreover, in the case of 2 dichroic mirrors, a spectral peak raises around $1 \mu \mathrm{m}$. This phenomenon has already been studied by J. Hermann and al. [14], already observed in Yb:CALGO [15], and originates from 
uncompensated group delay dispersion. This structure is also observed with a single dichroic mirror however at a much lower level. It is therefore the combined contribution of population inversion and uncontrolled GDD of dichroic mirror coating that explains the reduction of the spectral bandwidth with increasing OC.

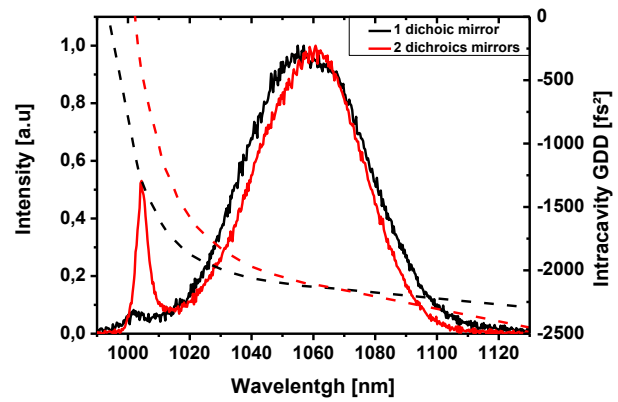

Fig. 3. Experimental output spectra obtained with $10 \%$ OC transmission and calculated intracavity GDD for one and two dichroic mirrors configuration

Further decreasing the pulse duration with higher OC to improve average power would require designing custom dichroic mirror with accurate GDD control.

From the above analysis, it is not surprising to achieve the shortest pulse duration with a 3\% OC. The spectrum is centered at $1063 \mathrm{~nm}$ with a spectral bandwidth of $51 \mathrm{~nm}$ and an average power of $90 \mathrm{~mW}$ with only $3.6 \mathrm{~W}$ of incident pump power. The spectrum displayed in figure 4.a is very smooth and exhibits a Gaussian shape. A tiny peak is visible at $1000 \mathrm{~nm}$ attributed to the remaining dichroic mirror.

(a)

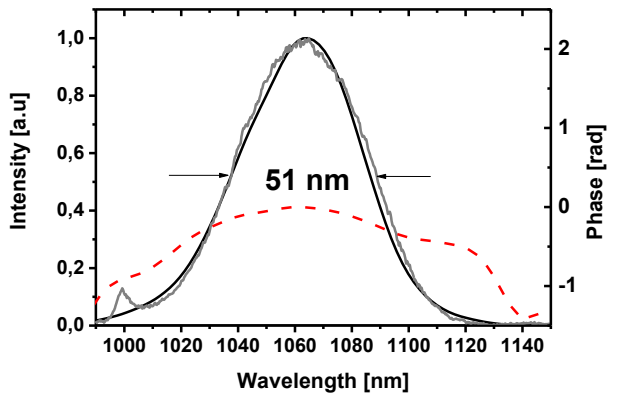

(b)

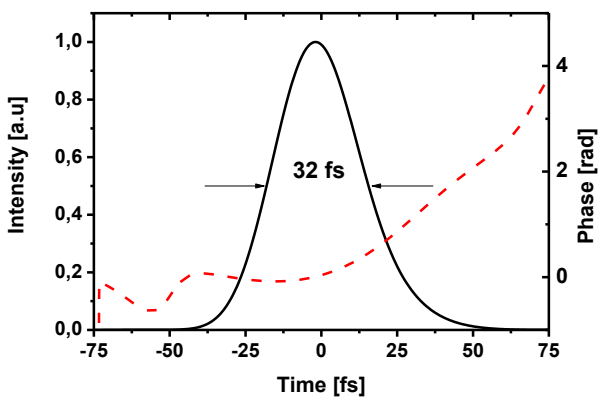

Fig. 4. a) Retrieved SHG-FROG spectrum (black curve) superimposed with the experimental spectrum (grey curve) and spectral phase (dashed red curve). b) Retrieved intensity profile (black curve) and temporal phase (dashed red curve) of the output pulses.
After external compression (-1000 $\left.\mathrm{fs}^{2}\right)$, the pulse is retrieved from a SHG-FROG measurement and leads to a Fourier transform limited pulse duration of $32 \mathrm{fs}$ and a time bandwidth product of 0.433 (see figure 4.b). Experimental and retrieved spectra are superimposed in figure 4.a with an excellent agreement.

In addition further characterizations (beam profile and pulse train stability) have been performed. We measured an output beam quality characterized by a factor $\mathrm{M}_{\mathrm{x}}{ }_{\mathrm{x}} \cdot \mathrm{M}_{\mathrm{y}}{ }_{\mathrm{y}}$ of $1.15 \mathrm{x} 1.2$ with no evidence of astigmatism. The mode-locking regime is stable during several hours. Figure 5 shows the corresponding radio frequency spectrum of the fundamental beat note at $96.25 \mathrm{MHz}$ recorded with a resolution bandwidth (RBW) of $3 \mathrm{kHz}$ and a $500 \mathrm{MHz}$ wide-span (inset) measured with a RBW $25 \mathrm{KHz}$ for the shortest pulse operation. The very high contrast $(70 \mathrm{dBm})$ and the absence of modulations in the wide span are evidences of a very stable and clean mode-locked operation of the Yb:CALGO oscillator.

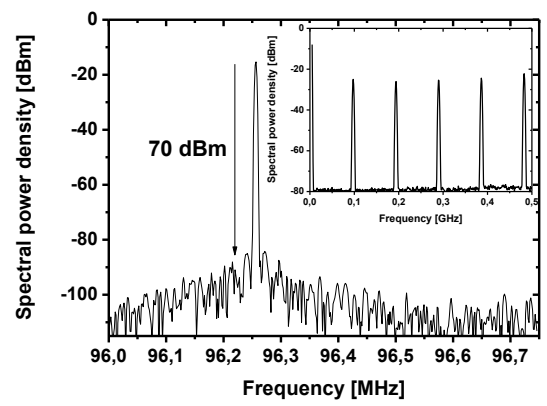

Fig. 5. Radio-frequency spectrum.

In the aim of decreasing the oscillator footprint, reducing the intracavity losses and improving its robustness, we discuss here the potential of using intracavity chirped mirror for ultra-short pulse generation. Chirped mirrors (-100 $\mathrm{fs}^{2}$ and $-250 \mathrm{fs}^{2}$ per bounce from Layertech) are inserted in each arm of the cavity and SF10 prisms are replaced by silica prisms separated by $120 \mathrm{~mm}$ to provide a fine intracavity GDD control. For $10 \mathrm{~W}$ of pump power, the oscillator delivers an average power of $1.5 \mathrm{~W}$ and pulses with a spectral bandwidth of $34 \mathrm{~nm}$ as shown in figure 6 (black curve).A pulse duration of $37 \mathrm{fs}$ is obtained after SHG-FROG measurement.

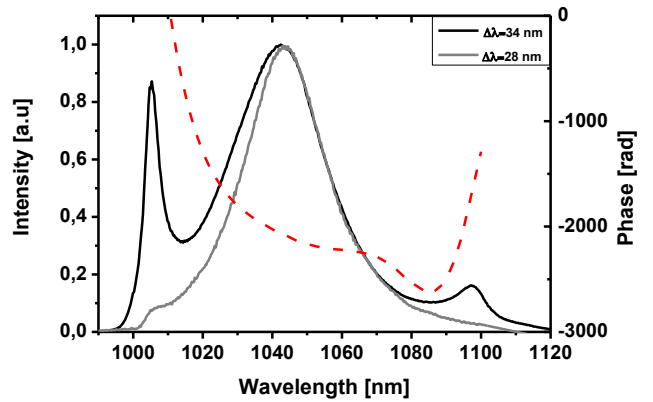

Fig. 6. Experimental spectra for $\mathrm{OC}=30 \%$ (black curve) and $\mathrm{OC}=40 \%$ (grey curve), calculated intracavity GDD (dashed red curve)

Sharp spectral structures appear at $1 \mu \mathrm{m}$ and $1.1 \mu \mathrm{m}$ caused by additional uncompensated high-order dispersion introduced by the chirped and dichroic mirrors (red curve). The structures are dissipated by reducing the intra-cavity peak power with an output 
coupler of $40 \%$. In this configuration, the oscillator provides an average power of $1 \mathrm{~W}$ and pulse duration of $43 \mathrm{fs}$ after external compression with a spectrum of $28 \mathrm{~nm}$ (see figure 6 (grey curve)). In the compact configuration with intracavity chirped mirrors, we obtained results very closed to the configuration with SF10 prisms and large OC values. We believe that shorter pulses could be obtained with custom broadband chirped mirrors where the GDD is controlled over the complete spectral bandwidth of Yb:CALGO.

In conclusion, we have presented the first pure Kerr-lens modelocked Yb:CALGO oscillator. Based on a powerful diffraction limited fiber pump laser, we have built a pure KLM oscillator at 96 $\mathrm{MHz}$ delivering sub-40 fs pulses at the watt level. The lack of optics with constant GDD over large spectral ranges forces us to use SF10 prisms only. In this configuration, we have investigated different $\mathrm{OC}$ to shorten the pulse duration. With an output coupler value of $3 \%$, our oscillator produced pulses with a duration of $32 \mathrm{fs}$ and 90 $\mathrm{mW}$ of output power after external recompression. Furthermore, these pulses exhibit a structure-free spectrum with a bandwidth of $51 \mathrm{~nm}$ centered at $1063 \mathrm{~nm}$. It is, to our best knowledge, the shortest pulse duration ever reported for $\mathrm{Yb}$-doped bulk material. This result is the combination of the excellent spectral properties of $\mathrm{Yb}$ :CALGO and the use of a high brightness pumping scheme allowing pure KLM operation. By designing specific ultra-large band GDD controlled chirped mirrors, the same characteristics could be attained in a prism free configuration. Similarly, custom designed dichroic mirror should produce ultimate pulse duration together with high average power.

We acknowledge the support from the European Community through the I3 LASERLAB III JRA Eurolite, the Conseil Régional d'Aquitaine with the "Lougre Brillant" program, Aquitaine Valorisation, the CNRS national networks FEMTO and CMDO+ through the entitled HABRY program, and the Agence Nationale de la Recherche (ANR) through the PAMPERO (ANR-12-B5090033) projects

\section{References}

1. F. Druon, F. Balembois, P. Georges, IEEE Photonics Journal 3, 268-273 (2011).

2. J. Petit, P. Goldner, and B. Viana, Opt. Lett. 30, 1345-1347 (2005).

3. A. Agnesi, A. Greborio, F. Pirzio, G. Reali, J. Aus der Au, and A. Guandalini, Opt. Express 20, 10077-10082 (2012).

4. A. Yoshida, A. Schmidt, V. Petrov, C. Fiebig, G. Erbert, J. Liu, H. Zhang, J. Wang, and U. Griebner, Opt. Lett. 36, 4425-4427 (2011).

5. Sadao Uemura and Kenji Torizuka, Jpn. J. Appl. Phys. 50, 010201 (2011).

6. C. J. Saraceno, C. Schriber, F. Emaury, O. H. Heckl, C. R. E.Baer, M. Hoffmann, K. Beil, C. Kränkel, M. Golling, T. Südmeyer, and U. Keller, Appl. Sci. 3, 355 (2013).

7. A. Diebold, F. Emaury, C. Schriber, M. Golling, C. Saraceno, T. Südmeyer, and U. Keller, Opt. Lett. 38, 3842-3845 (2013).

8. G. Machinet, P. Sevillano, F. Guichard, R. Dubrasquet, P. Camy, J. Doualan, R. Moncorgé, P. Georges, F. Druon, D. Descamps, and E. Cormier, Opt. Lett. 38, 4008-4010 (2013).

9. J. Boullet, Y. Zaouter, R. Desmarchelier, M. Cazaux, F. Salin, J. Saby, R. Bello-Doua, and E. Cormier, Opt. Express 16, 17891-17902 (2008).

10. F. Druon, M. Olivier, A. Jaffrès, P. Loiseau, N. Aubry, J. DidierJean, F. Balembois, B. Viana, and P. Georges, Opt. Lett. 38, 4138-4141 (2013).

11. T. Brabec, C. Spielmann, and F. Krausz, Opt. Lett. 16, 1961-1963 (1991).

12. T. Brabec, C. Spielmann, P. Curley, and F. Krausz, Opt. Lett. 17, $1292-$ 1294 (1992).

13. J. Boudeile, F. Druon, M. Hanna, P. Georges, Y. Zaouter, E. Cormier, J. Petit, P. Goldner, B. Viana, Opt. Lett. 32, 19623-1964, (2007).
14. J. Herrmann, V. Kalosha, and M. Müller, Opt. Lett. 22, 236-238 (1997). 15. Y. Zaouter, J. Didierjean, F. Balembois, G. Lucas Leclin, F. Druon, P. Georges, J. Petit, P. Goldner and B. Viana, Opt. Lett. 31, 119-121 (2006). 
1. F. Druon, F. Balembois, P. Georges, "New materials for short-pulse amplifiers", IEEE Photonics Journal 3, 268-273 (2011).

2. J. Petit, P. Goldner, and B. Viana, "Laser emission with low quantum defect in Yb:CaGdAlO4", Opt. Lett. 30, 1345-1347 (2005).

3. A. Agnesi, A. Greborio, F. Pirzio, G. Reali, J. Aus der Au, and A. Guandalini, "40-fs Yb3+:CaGdAlO4 laser pumped by a single-mode 350mW laser diode", Opt. Express 20, 10077-10082 (2012).

4. A. Yoshida, A. Schmidt, V. Petrov, C. Fiebig, G. Erbert, J. Liu, H. Zhang, J. Wang, and U. Griebner, "Diode-pumped mode-locked Yb:YCOB laser generating 35 fs pulses," Opt. Lett. 36, 4425-4427 (2011).

5. Sadao Uemura and Kenji Torizuka, "Sub-40-fs Pulses from a DiodePumped Kerr-Lens Mode-Locked Yb-Doped Yttrium Aluminum Garnet Laser” Jpn. J. Appl. Phys. 50, 010201 (2011).

6. C. J. Saraceno, C. Schriber, F. Emaury, O. H. Heckl, C. R. E.Baer, M. Hoffmann, K. Beil, C. Kränkel, M. Golling, T. Südmeyer, and U. Keller, "Cutting-Edge High-Power Ultrafast Thin Disk Oscillators", Appl. Sci. 3, 355 (2013).

7. A. Diebold, F. Emaury, C. Schriber, M. Golling, C. Saraceno, T. Südmeyer, and U. Keller, "SESAM mode-locked Yb:CaGdAlO4 thin disk laser with 62 fs pulse generation", Opt. Lett. 38, 3842-3845 (2013).

8. G. Machinet, P. Sevillano, F. Guichard, R. Dubrasquet, P. Camy, J. Doualan, R. Moncorgé, P. Georges, F. Druon, D. Descamps, and E. Cormier, "High-brightness fiber laser-pumped 68 fs - $2.3 \mathrm{~W}$ Kerr-lens mode-locked Yb:CaF2 oscillator", Opt. Lett. 38, 4008-4010 (2013).

9. J. Boullet, Y. Zaouter, R. Desmarchelier, M. Cazaux, F. Salin, J. Saby, R. Bello-Doua, and E. Cormier, "High power ytterbium-doped rod-type threelevel photonic crystal fiber laser", Opt. Express 16, 17891-17902 (2008).

10. F. Druon, M. Olivier, A. Jaffrès, P. Loiseau, N. Aubry, J. DidierJean, F. Balembois, B. Viana, and P. Georges, "Magic mode switching in Yb:CaGdAlO4 laser under high pump power", Opt. Lett. 38, 4138-4141 (2013).

11. T. Brabec, C. Spielmann, and F. Krausz, "Mode locking in solitary lasers," Opt. Lett. 16, 1961-1963 (1991).

12. T. Brabec, C. Spielmann, P. Curley, and F. Krausz, "Kerr lens mode locking", Opt. Lett. 17, 1292-1294 (1992).

13. J. Boudeile, F. Druon, M. Hanna, P. Georges, Y. Zaouter, E. Cormier, J. Petit, P. Goldner, B. Viana, "Continuous-wave and femtosecond laser opertation of $\mathrm{Yb}$ :CaGdAlO4 under high-power diode pumping", Opt. Lett. 32, 19623-1964, (2007).

14. J. Herrmann, V. Kalosha, and M. Müller, "Higher-order phase dispersion in femtosecond Kerr-lens mode-locked solid-state lasers: sideband generation and pulse splitting", Opt. Lett. 22, 236-238 (1997).

15. Y. Zaouter, J. Didierjean, F. Balembois, G. Lucas Leclin, F. Druon, P. Georges, J. Petit, P. Goldner and B. Viana "47-fs diode-pumped Yb3+:CaGdAlO4 laser”, Opt. Lett. 31, 119-121 (2006). 